\title{
EFEITO DA ACIDEZ E DE MODIFICADORES ORGÂNICOS NA DETERMINAÇÃO DE METILXANTINAS: UM EXPERIMENTO DE CROMATOGRAFIA LIQUIDA DE ALTA EFICIÊNCIA (CLAE) EMPREGANDO OTIMIZAÇÃO UNI E MULTIVARIADA
}

\author{
Nádia Machado de Aragão \\ Departamento de Química e Exatas, Campus de Jequié, Universidade Estadual do Sudoeste da Bahia, Av. José Moreira Sobrinho, \\ s/n, 45206-510 Jequié - BA, Brasil \\ Márcia Cristina da Cunha Veloso e Marcia Sousa Bispo \\ Departamento de Química, Instituto Federal de Educação, Ciência e Tecnologia, 40625-650 Salvador-BA, Brasil \\ Jailson Bittencourt de Andrade* \\ Instituto de Química, Universidade Federal da Bahia, Campus de Ondina, 40170-115 Salvador-BA, Brasil
}

Recebido em 10/11/08; aceito em 24/5/09; publicado na web em 19/11/09

\begin{abstract}
THE ROLE OF ACIDITY AND ORGANIC MODIFIERS IN THE METHYLXANTHINES DETERMINATION: A HPLC EXPERIMENT. In this work a new experiment using HPLC is proposed in order to explore the role of acidity and the organic modifiers in the determination of methylxanthines in tea and coffee. Multivariate and univariate optimizations of the experimental conditions were used.
\end{abstract}

Keywords: methylxanthines; HPLC; caffeine.

\section{INTRODUÇÃO}

Até o final da década de 70 a cromatografia liquida de alta eficiência (CLAE) era pouco utilizada no Brasil, tornando-se mais popular a partir do desenvolvimento de novas fases estacionárias, como a fase reversa quimicamente ligada, que associadas ao uso de eluição gradiente e ao desenvolvimento de detectores mais seletivos e sensíveis, tornou possível a separação de uma gama de substâncias a partir de matrizes complexas como alimentos, fluidos biológicos e solo. ${ }^{1-3}$

A atual importância da técnica pode ser facilmente reconhecida pelo enorme número de publicações científicas que tratam do desenvolvimento do método e, principalmente, da sua utilização. Os importantes avanços da CLAE devido ao seu acoplamento à espectrometria de massas (CLAE-EM) e à diminuição do seu custo operacional, fazem com que seja amplamente utilizada tanto em laboratórios de pesquisa e de análises clínicas, como em complexos industriais. Em vista dessa grande aplicação, torna-se cada vez mais importante que a mesma seja abordada nos cursos técnicos e de graduação em Química e áreas afins.

Um grupo de substâncias que se adequa facilmente a experimentos voltados para o treinamento hands on são as metilxantinas, que são alcaloides naturalmente presentes em plantas utilizadas na obtenção de bebidas alimentícias ou estimulantes consumidos em todo o mundo. ${ }^{4-6}$

As metilxantinas são originárias de bases púricas, sendo derivados metilados da 2,6-dioxipurina ou xantina. De modo geral, estas substâncias possuem uma estrutura básica onde os hidrogênios nas posições 1,3 e 7 são trocados por substituintes metílicos, sendo as mais abundantes a cafeína (1,3,7- trimetilxantina), e as isoméricas teofilina (1,3-dimetilxantina) e a teobromina (3,7-dimetilxantina) ${ }^{6}$ (Figura 1). Entretanto, podem também possuir um caráter anfótero, comportando-se como ácidos ou bases em função do $\mathrm{pH}$, como no caso da teofilina e da teobromina que possuem, respectivamente, um hidrogênio ácido ligado ao nitrogênio do anel do imidazol e ao nitrogênio imídico do anel de seis membros. ${ }^{7}$

*e-mail: jailsong@ufba.br<smiles>O=C1C2N=CN(I)N2C(=O)N1I</smiles>

xantina

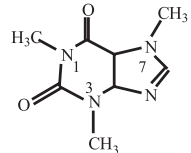

cafeína

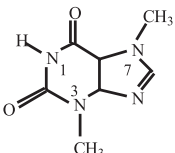

teobromina<smiles>CN1C=NC2C1N(C)C(=O)N2C</smiles>

teofilina
Figura 1. Estruturas da xantina e derivados metilados: 1. xantina; 2. cafeína; 3. teobromina; 4. teofilina

Neste trabalho é proposto um experimento de CLAE no qual é possível comparar a influência de diferentes fases móveis e da acidez, utilizando técnicas de planejamento univariado e/ou multivariado. Os modificadores orgânicos utilizados foram metanol (considerado um bom eluente para CLAE devido a sua baixa viscosidade) e etanol, pela sua característica biorrenovável. As amostras utilizadas foram chás e café adquiridos no mercado local, que não trazem riscos para o meio ambiente ou para a saúde do aluno.

\section{PARTE EXPERIMENTAL}

\section{Equipamentos e materiais}

Cromatógrafo a líquido de alta eficiência, Perkin Elmer série 200 equipado com injetor Rheodyne (Cotati, Califórnia, USA) com loop de $20 \mu \mathrm{L}$; detector UV-Visível modelo Perkin Elmer série 200; coluna cromatográfica Lichrospher 100 RP-18 (244 x 4,4 mm, d.i. $5 \mu \mathrm{m})$, acoplada com pré-coluna Lichrospher (4 x $4 \mathrm{~mm}$ ). Aparelho digital de ponto de fusão, Microquímica - MQAPF-301; filtros de celulose (Whatman 41, 0,45 $\mu \mathrm{m}$ ); balança analítica Sartorius A 120 s; sistema de filtração Millipore para solventes orgânicos HA, 0,45 $\mu \mathrm{m}$; ultrapurificador de água, Nanopure Diamond, Barnstesd Modelo D11911; freezer.

\section{Reagentes e solventes}

Metanol, etanol, acetonitrila (grau cromatográfico, 99,9\%) e ácido acético glacial foram obtidos da Merck. Cafeína (Carlo Erba, Milão, Itália) purificada por sublimação ${ }^{8}$ (uma alternativa para obtenção de 
cafeína é extração a partir de folhas chá preto com diclorometano, e purificação por sublimação) ${ }^{9}$ teobromina (M\&B) purificada por recristalização; teofilina (Sigma-Aldrich) purificada por recristalização (esta pode ser obtida também a partir de fármacos comerciais, tais como broncodilatadores, por meio de extração com solventes).

\section{Preparação de soluções padrão}

Solução padrão estoque foi preparadas, pesando-se $0,040 \mathrm{~g}$ de cada metilxantina (cafeína, teobromina e teofilina) e dissolvendo-se em 50 $\mathrm{mL}$ de uma mistura: água/etanol/ácido acético (75/24/1\% v/v/v). Após completar o volume para $200 \mathrm{ml}$ em balão volumétrico, a solução foi filtrada em membranas de $0,45 \mu \mathrm{m}$ ou em papel Whatman 41 (filtro duplo). Estas soluções se estocadas sob refrigeração são estáveis por 8 meses. A partir das soluções padrão estoques, foram preparadas soluções de trabalho mistas com as três metilxantinas na faixa de $2-30 \mu \mathrm{g} \mathrm{mL} \mathrm{L}^{-1}$.

\section{Preparo da fase móvel}

Sugere-se preparar pequenos volumes de fase móvel (FM) uma vez que é utilizado o sistema de eluição isocrático e que as mesmas podem ser recicladas. As FM a serem testadas podem ser preparadas em provetas. As FM devem ser filtradas e desgaseificadas.

Atenção: durante a preparação da FM os componentes deverão ser medidos separadamente e só depois misturados, uma vez que não é correto medir o volume de um dos componentes em uma proveta e depois avolumar com o segundo componente, na mesma proveta. A ação de forças intermoleculares ${ }^{10}$ pode levar à contração do volume.

\section{Preparo das amostras}

Para as amostras de chás, foram feitas infusões, em $150 \mathrm{~mL}$ de água fervente, de quantidades informadas na embalagem (geralmente, um saco pequeno), visando reproduzir as condições mais comuns de consumo. Para as amostras de café, cerca de 1,0 g de café solúvel (aproximadamente uma colher de chá) foi dissolvido em 150,0 mL de água fervente. Os extratos obtidos, após filtração, foram injetados diretamente no sistema cromatográfico.

\section{RESULTADOS E DISCUSSÃO}

Na otimização de métodos de análise por cromatografia, uma das metas é o equilíbrio entre o menor tempo de análise e uma melhor resolução. A resolução, $R_{s}$, é a medida quantitativa da separação de dois picos adjacentes, sendo calculada a partir da Equação 1:

$\mathrm{R}_{\mathrm{s}}=2 \Delta \mathrm{t} /\left(\mathrm{tw}_{1}+\mathrm{tw}_{2}\right)$

onde: $\Delta \mathrm{t}$ é a medida da separação dos máximos de dois picos adjacentes; e tw e tw $_{2}$ são as larguras das bases dos picos, obtidas tangenciando-se as gaussianas até que interceptem a linha base.

Quando $\mathrm{R}_{\mathrm{s}}=1,0$, os dois picos estão, razoavelmente, separados e quanto maior o valor de $\mathrm{R}_{\mathrm{s}}$, melhor será a separação entre picos de substâncias que eluem seguidamente. Na Figura 2 estão representados os parâmetros utilizados no cálculo da resolução $\mathrm{R}_{\mathrm{s}}$ entre dois picos cromatográficos. ${ }^{1,11}$

Deste modo, duas respostas analíticas, para estudos de otimização de um método, podem ser consideradas: $\mathrm{R}_{\mathrm{s}}$ (resolução cromatográfica entre dois analitos, que no caso deste experimento são as metilxantinas isoméricas teobromina e teofilina) e R/tA (resolução cromatográfica $\left(R_{s}\right)$ entre teobromina e teofilina em função do tempo total de análise( $\mathrm{tA})$ ).

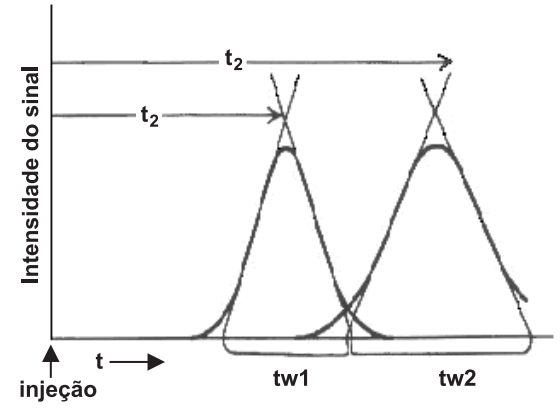

Figura 2. Ilustração da determinação da resolução onde $t_{w 1}$ e $t_{w 2}$ são as larguras das bases dos picos, obtidas tangenciando-se as gaussianas até que interceptem a linha base; $t_{1}$ e $t_{2}$ são os tempos de retenção medidos pelas distâncias entre os máximos dos picos e o início da injeção da amostra

A resolução cromatográfica é influenciada por três parâmetros experimentais: $\mathrm{N}$ (número de pratos teóricos ou eficiência), $\mathrm{k}$ (fator de retenção) e $\alpha$ (seletividade) conforme Equação $2^{1}$ :

$\mathrm{R}_{\mathrm{s}}=\mathrm{N}^{1 / 2} / 4\left[\mathrm{k}_{2} /\left(\mathrm{k}_{2}+1\right)\right][(\alpha-1) / \alpha]$

Otimização univariada do fator de retenção (k) na separação das metilxantinas por CLAE-fase reversa (FR)

A força cromatográfica da FM está relacionada à fase estacionária utilizada e sua modulação é feita empiricamente, partindo-se, normalmente de uma fase móvel com força elevada. Considerando-se que o experimento proposto foi realizado utilizando-se uma mesma coluna com fase estacionária ligada apolar (onde o fator $\mathrm{N}$ não será alterado), começou-se com uma proporção elevada do solvente menos polar, que no caso foi o modificador orgânico (metanol ou etanol). Assim, podem-se testar várias proporções entre modificadores orgânicos e água na separação das metilxantinas.

Inicialmente a fase móvel metanol:água (40:60; v/v), pH aparente 6,14, foi utilizada na separação e quantificação de cafeína em amostras de chás e café. ${ }^{12}$ Entretanto, no caso de misturas de metilxantinas, esta fase móvel permite uma boa separação de cafeína, mas não consegue separar as metilxantinas isoméricas teofilina e teobromina, que coeluem (Figura 3). Nesse sentido, foi feita a tentativa de diminuir a força cromatográfica da FM, diminuindo-se a proporção do modificador orgânico.

A mudança da composição da fase móvel para metanol:água (30:70 ; v/v), ou metanol:água $(20: 80 ; \mathrm{v} / \mathrm{v})$ não alterou o perfil do cromatograma, resultando apenas em aumento nos tempos de retenção das substâncias ${ }^{13}$ (Figura 3). Portanto, a alteração do fator k não melhorou a resolução cromatográfica entre as duas metilxantinas isoméricas. Partiu-se então para a otimização da seletividade $(\alpha)$.

\section{Otimização univariada da seletividade $(\alpha)$}

Efeito do pH na separação das metilxantinas por CLAE-FR

Devido à possibilidade de protonação das metilxantinas, resultando em espécies iônicas estabilizadas por efeitos indutivos e ressonantes, pode-se sugerir que o aumento da acidez da fase móvel pode influir na separação. ${ }^{13}$

Para avaliar a influência do $\mathrm{pH}$ foi escolhido o ácido acético por suas características não tóxicas e pouco agressivas ao sistema de CLAE. A alteração da composição da fase móvel metanol:água (20:80; v/v) para metanol:água:ácido acético (20:79:1; v/v/v) resultou num $\mathrm{pH}<4$, não havendo uma boa resolução entre as metilxantinas isoméricas (Figura 4). 


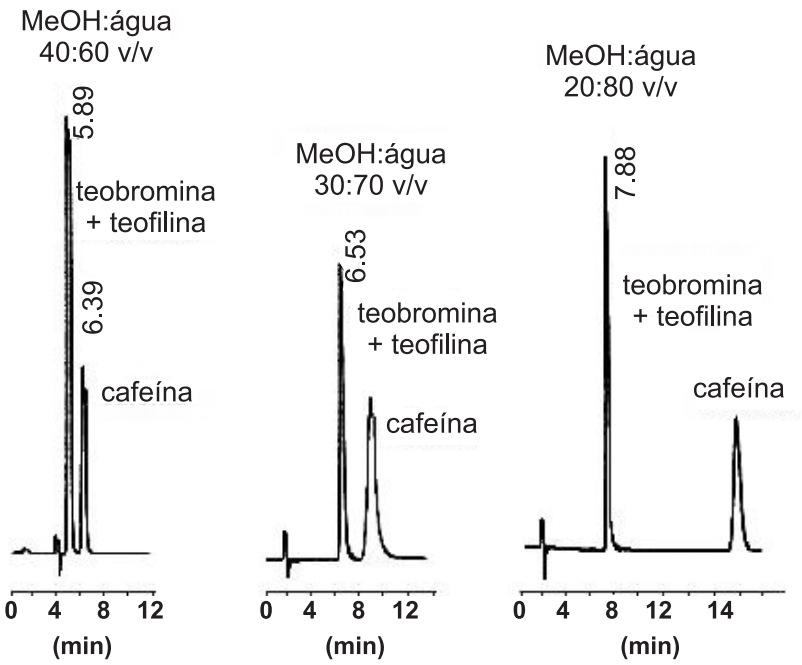

Figura 3. Separação de metilxantinas utilizando metanol (MeOH) e água como fase móvel

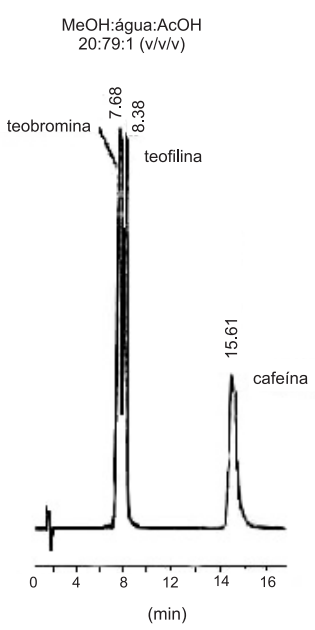

Figura 4. Separação de metilxantinas utilizando metanol, água e ácido acético (AcOH) como fase móvel

Utilizando-se a fase móvel metanol:água:ácido acético (20:75:5; v/v/v), à vazão de $1,0 \mathrm{~mL} \mathrm{~min}^{-1}$, foi possível separar as três metilxantinas, em um tempo de análise de 14 min (Figura 4), revelando o efeito positivo da acidez da fase móvel na separação das metilxantinas, especialmente as isoméricas que apresentaram $R_{\mathrm{s}}=2$.

Adicionalmente, pode ser observado na Figura 4 que as metilxantinas isoméricas, que se comportam como bases fracas, eluiram numa ordem que está de acordo com as suas características estruturais. De acordo com a relação sigmoidal entre k versus $\mathrm{pH}$ para bases fracas, os k diminuem com a diminuição do $\mathrm{pH}$ das FM. A teobromina é mais básica que a teofilina, devido ao efeito eletroindutor do grupo metil presente no anel imidazólico. Deste modo, em meio ácido a teobromina (com constante de protonação em solução aquosa igual a log $\mathrm{K}=10,5)^{14}$ encontra-se mais ionizada que a teofilina (com constante de protonação em solução aquosa igual a $\log \mathrm{K}=8,6)^{14}$, e como foi usada uma fase estacionária apolar (fase reversa), a teobromina elui antes da teofilina.

\section{Efeito do modificador orgânico}

Como modificador orgânico foi escolhido o etanol por ser de baixa toxicidade e proveniente de fontes renováveis, mantendo-se a vazão de 1,0 $\mathrm{mL} \min ^{-1}$ e a mesma composição da fase móvel: etanol:água:ácido acético (20:75:5; v/v/v). A troca de metanol por etanol reduziu significativamente o tempo total de análise cromatográfica de 14 para cerca de 6 min (Figura 5) sem perda significativa na resolução cromatográfica das metilxantinas isoméricas $\left(\mathrm{R}_{\mathrm{s}}=1,0\right)$.

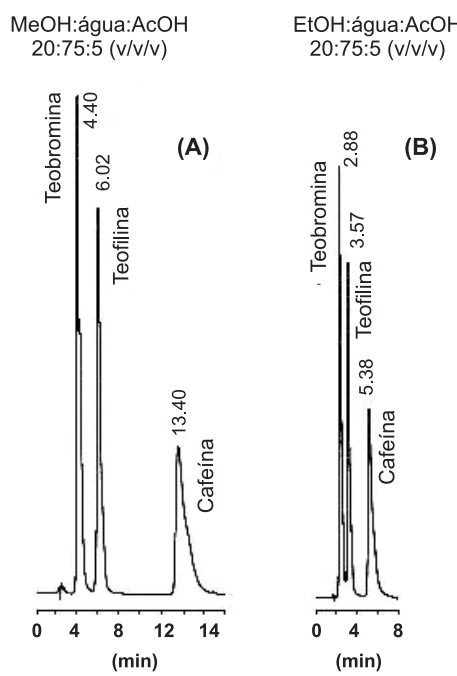

Figura 5. Cromatogramas obtidos com os diferentes modificadores orgânicos: [modificador orgânico A ou B:água:ácido acético $(20: 75: 5 ; v / v / v)]$. (A) metanol (MeOH), (B) etanol (EtOH)]

Considerando-se que, neste caso, a etapa crítica de resolução foi entre a teofilina e teobromina, a relação $\mathrm{R} / \mathrm{t}$ A foi de 0,14 quando o modificador orgânico foi o metanol, ao passo que quando o etanol foi utilizado a relação $\mathrm{R} / \mathrm{t}$ A passou para 0,18 revelando que, nas condições deste trabalho, o etanol foi o melhor modificador orgânico.

\section{Otimização multivariada}

O uso de planejamento multivariado tem sido bastante difundido em várias técnicas analíticas ${ }^{15-18} \mathrm{e}$ foi aplicado para obter as condições otimizadas de composição (etanol:água:ácido acético) e vazão da fase móvel, na separação de metilxantinas em amostras complexas.

O planejamento fatorial completo em três níveis é um modelo matemático que descreve superfícies de respostas curvas, permitindo, já no planejamento fatorial, a obtenção dos pontos que produzem melhores respostas analíticas (valores otimizados). Assim, o planejamento fatorial completo em três níveis, para otimização de duas variáveis, torna-se mais simples e rápido quando comparado a outros planejamentos, além de requerer um número reduzido de experimentos $(\mathrm{n}=9$ experimentos $) .{ }^{15-18}$

Dessa forma pode ser estudada a influência das seguintes variáveis: acidez da fase móvel (em diferentes concentrações de ácido acético) e vazão da fase móvel. Os níveis máximos e mínimos de acidez e vazão da fase móvel estão representados nas Tabelas 1 e 2. A resposta que se desejou otimizar foi a resolução cromatográfica entre as três metilxantinas, partindo-se como padrão uma composição previamente estabelecida (etanol:água:ácido acético). ${ }^{17}$ Os resultados deste planejamento foram avaliados usando análise de variância (ANOVA) e foram processados empregando-se o programa computacional Estatística 5.5. ${ }^{19}$

\section{Otimização da acidez e vazão da fase móvel}

Considerando-se o tempo como um fator relevante em qualquer análise química, nos estudos de otimização foi considerada 
Tabela 1. Níveis de acidez e vazão da fase móvel empregados na primeira etapa do planejamento experimental

\begin{tabular}{lccc}
\hline Variáveis & Baixo (-) & Médio $(0)$ & Alto $(+)$ \\
\hline \% ácido acético & 2,0 & 6,0 & 10 \\
Vazão $\left(\mathrm{mL} \mathrm{min}^{-1}\right)$ & 1,0 & 1,1 & 1,2 \\
\hline
\end{tabular}

Tabela 2. Níveis de acidez e vazão da fase móvel empregados na segunda etapa do planejamento experimental

\begin{tabular}{lccc}
\hline Variáveis & Baixo (-) & Médio(0) & Alto (+) \\
\hline \% ácido acético & 0,5 & 1,0 & 1,5 \\
Vazão $\left(\mathrm{mL} \min ^{-1}\right)$ & 1,0 & 1,1 & 1,2 \\
\hline
\end{tabular}

a resposta analítica $\mathrm{R}_{\mathrm{s}} / \mathrm{tA}$. No estudo da acidez da fase móvel, diferentes concentrações de ácido acético foram usadas (Tabelas 1 e 2). Para as concentrações de ácido acético descritas na Tabela 1, os resultados em termos de gráfico de contorno (Figura 6), mostraram melhores respostas com concentrações, de ácido acético, menores que $2 \%$ e maiores valores de vazão. Desta forma, novos experimentos foram realizados empregando-se as concentrações descritas na Tabela 2. O gráfico de contorno apresentado na Figura 7 mostra que as melhores respostas foram obtidas com concentração de ácido acético em torno de 1,0\% e maiores valores de vazão $\left(>1,2 \mathrm{~mL} \mathrm{~min}^{-1}\right)$. A resolução de 1,28, entre as duas metilxantinas isoméricas (teobromina e teofilina), apresentada na Tabela 4 , foi obtida nas condições de vazão de $1,0 \mathrm{~mL} / \mathrm{min}$ e composição da fase móvel contendo 1,0\% de ácido acético, ou seja, etanol:água:ácido acético (24:75:1; v/v/v). As Tabelas 3 e 5 apresentam os resultados obtidos com as demais condições do planejamento experimental. O gráfico de contorno que representa estes resultados é mostrado na Figura 7.

A relação entre a acidez da fase móvel $(\mathrm{F})$, a vazão $(\mathrm{V})$ e a resposta analítica como resolução cromatográfica entre teobromina e teofilina em função do tempo total de análise (Rs/tA) é representada pela Equação 3:

$\mathrm{Rs} / \mathrm{tA}=0,276519+0,012278 \mathrm{~F}-0,033611 \mathrm{~F}^{2}+0,036389 \mathrm{~V}-$ $0,011944 \mathrm{~V}^{2}$

Derivando esta equação em função das variáveis, pode-se chegar às condições ótimas de acidez (em termos da concentração de ácido acético na fase móvel) e vazão da fase móvel, obtidas a partir das Equações 4 e 5:

$\partial \mathrm{Rs} / \mathrm{tA} / \partial \mathrm{F}=0,012278-2(0,033611) \mathrm{F}=0$

$\partial \mathrm{Rs} / \mathrm{tA} / \partial \mathrm{V}=0,036389-2(0,011944) \mathrm{V}=0$

Logo, os valores codificados para composição da fase móvel são, em termos da concentração de ácido acético e vazão, respectivamente: $\mathrm{F}=0,18$ e $\mathrm{V}=1,52$.

Descodificando estes valores, a partir da Equação 6:

$\mathrm{C}_{\mathrm{i}}=\left|\mathrm{X}_{\mathrm{i}}-\mathrm{X}_{\mathrm{i}}^{\circ} / \mathrm{CX} \mathrm{i}_{\mathrm{i}}\right| \mathrm{K}$

onde: $\mathrm{C}_{\mathrm{i}}=$ valor codificado; $\mathrm{X}_{\mathrm{i}}=$ valor real; $\mathrm{X}_{\mathrm{i}}{ }^{\mathrm{o}}=$ valor central do planejamento; $\mathrm{CX}_{\mathrm{i}}=$ passo central do planejamento; $\mathrm{K}=$ valor codificado máximo que a variável pode assumir.

Os valores críticos, que representam as respostas ótimas, aparecem dentro do domínio experimental e correspondem aos valores: $\mathrm{F}$ $=1,1 \%$ de ácido acético na fase móvel e vazão, $\mathrm{V}=1,25 \mathrm{~mL} \mathrm{~min}{ }^{-1}$.

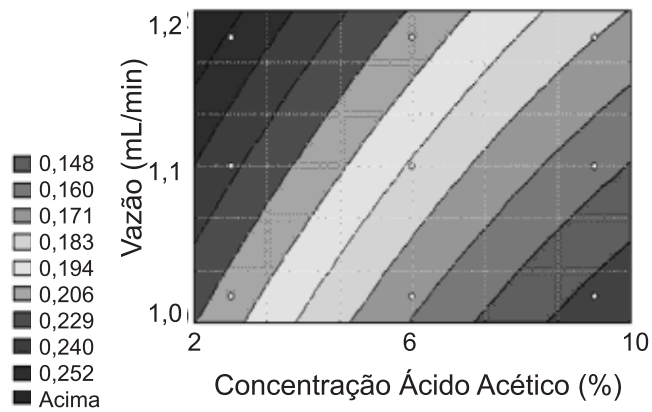

Figura 6. Gráfico de contorno no estudo de acidez da fase móvel (concentração de ácido acético entre 2 e 10\% v/v) com a vazão, considerando a razão entre a resolução cromatográfica entre teobromina e teofilina e o tempo total da análise, como resposta analítica

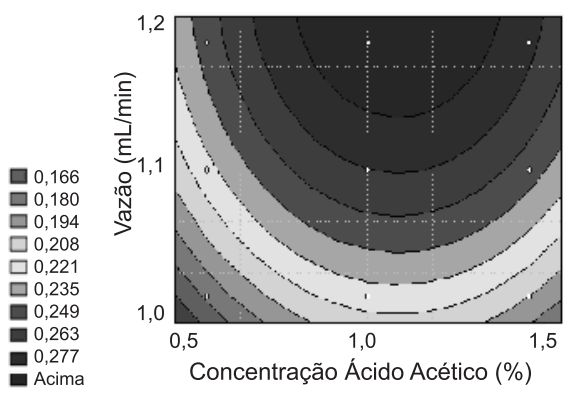

Figura 7. Gráfico de contorno no estudo de acidez da fase móvel (concentração de ácido acético entre 0,5 e 1,5\% v/v) com a vazão, representando as condições otimizadas do método analítico, considerando a razão entre a resolução cromatográfica entre teobromina e teofilina e o tempo total da análise, como resposta analítica

Tabela 3. Resolução cromatográfica entre teobromina e teofilina com fase móvel contendo $1,5 \%$ de ácido acético

\begin{tabular}{lcc}
\hline $\begin{array}{l}\text { Vazão } \\
\left(\mathrm{mL} \min ^{-1}\right)\end{array}$ & $\begin{array}{c}\text { Resolução } \\
(\mathrm{Rs})\end{array}$ & $\begin{array}{c}\text { Tempo total de análise } \\
(\mathrm{tA})(\mathrm{min})\end{array}$ \\
\hline 1,0 & 1,10 & 5,90 \\
1,1 & 1,14 & 5,28 \\
1,2 & 1,28 & 4,94 \\
\hline
\end{tabular}

Tabela 4. Resolução cromatográfica entre teobromina e teofilina com fase móvel contendo $1,0 \%$ de ácido acético.

\begin{tabular}{lcc}
\hline $\begin{array}{l}\text { Vazão } \\
\left(\mathrm{mL} \min ^{-1}\right)\end{array}$ & $\begin{array}{c}\text { Resolução } \\
(\mathrm{Rs})\end{array}$ & $\begin{array}{c}\text { Tempo total de análise } \\
(\mathrm{tA})(\mathrm{min})\end{array}$ \\
\hline 1,0 & 1,28 & 6,70 \\
1,1 & 1,30 & 6,24 \\
1,2 & 1,32 & 5,78 \\
\hline
\end{tabular}

Tabela 5. Resolução cromatográfica entre teobromina e teofilina com fase móvel contendo $0,5 \%$ de ácido acético

\begin{tabular}{lcc}
\hline $\begin{array}{l}\text { Vazão } \\
\left(\mathrm{mL} \min ^{-1}\right)\end{array}$ & $\begin{array}{c}\text { Resolução } \\
(\mathrm{Rs})\end{array}$ & $\begin{array}{c}\text { Tempo total de análise } \\
(\mathrm{tA})(\mathrm{min})\end{array}$ \\
\hline 1,0 & 1,12 & 6,77 \\
1,1 & 1,12 & 6,21 \\
1,2 & 1,29 & 5,74 \\
\hline
\end{tabular}


Entretanto, como altas vazões da fase móvel aumentam a pressão do sistema, a resolução cromatográfica de 1,28 (Tabela 4) foi considerada como satisfatória para a separação das metilxantinas isoméricas. Portanto, as condições otimizadas utilizadas foram: composição da fase móvel: etanol:água:ácido acético (24:75:1; v/v/v) e vazão de $1,0 \mathrm{~mL} \mathrm{~min}^{-1}$.

Os experimentos realizados sob as condições ótimas de vazão e acidez da fase móvel, para diversas soluções padrão, apresentaram cromatogramas similares ao mostrado na Figura 8, em que, no tempo de 6 min, teobromina, teofilina e cafeína são separadas cromatograficamente.

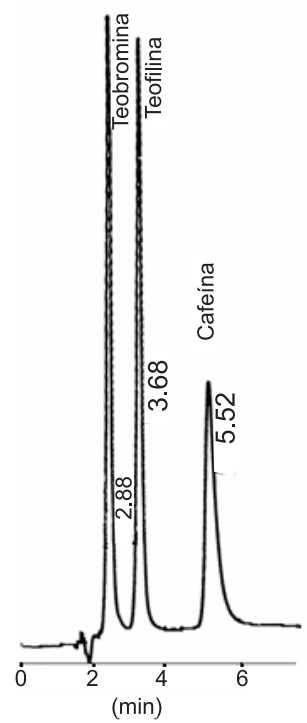

Figura 8. Cromatograma por CLAE-FR para solução de metilxantinas, nas condições otimizadas do método [etanol:água:ácido acético $(24: 75: 1 \% \mathrm{v} / \mathrm{v} / \mathrm{v}$, respectivamente e vazão $\left.1,0 \mathrm{~mL} \mathrm{~min}^{-1}\right]$

\section{CONCLUSÃO}

O uso do etanol e de água, no lugar de eluentes tóxicos e caros, como o metanol e a acetonitrila, que tradicionalmente são utilizados em CLAE, associados à eluição isocrática, que possibilita que a fase móvel possa ser reciclada e utilizada em mais de uma análise, permite ilustrar aos alunos os princípios da química segura, o uso de recursos renováveis e a diminuição na geração de efluentes tóxicos. O uso do etanol como modificador orgânico da fase móvel, embora tendo algumas implicações como a sua alta viscosidade que resulta em aumento da pressão total do sistema, mostrou-se viável na separação das metilxantinas estudadas. A sua utilização é satisfatória frente a outros solventes empregados com maior frequência, como o metanol e a acetonitrila, que embora apresentem menores viscosidades, são de maior toxicidade e maior custo.
A otimização do método, usando o planejamento fatorial completo em três níveis, permite o contato dos estudantes com técnicas estatísticas multivariadas e a obtenção de resultados eficientes e rápidos para determinação dos parâmetros que afetam a análise.

Como sugestão podem-se aplicar os métodos univariado e multivariado em amostras de chás e café solúvel, focalizando procedimentos simples para determinação e avaliação dos diversos parâmetros empregados na validação de um método analítico.

\section{AGRADECIMENTOS}

Ao PRONEX/FAPESB/CNPq, CAPES e FINEP pelo auxílio financeiro.

\section{REFERÊNCIAS}

1. Collins, C. H.; Braga, G. L.; Bonato, P. S.; Fundamentos de Cromatografia, Ed. Unicamp: Campinas, 2006.

2. Ciola, R.; Fundamentos da Cromatografia a Líquido de Alto Desempenho, Ed. Edgard Blücher: São Paulo, 1998, p. 179.

3. Sakairi, M.; Kambara, H.; Anal. Chem. 1988, 60, 774.

4. Griffiths, R. R.; Vernotica, P. M.; Arch. Farm. Med. 2000, 9, 727.

5. Gennaro, M. C.; Abrigo, C.; J. Anal. Chem. 1992, 343, 523.

6. Pereira, A. S.; Bicalho, B.; Lilla, S.; De Nucci, G.; Quim. Nova 2005, $28,5107$.

7. Simões, C. M. O.; Schenkel, E. P.; Gosmann, G.; de Mello, J. C. P.; Mentz, L. A.; Petrovick, P. R.; Farmacognosia da planta ao medicamento, 2a ed., Ed. UFRGS/Ed. UFSC: Porto Alegre/ Florianópolis, 2000, p. 641-656, 723-738.

8. Laswick, P. H.; Laswick, J. A.; J. Chem. Educ. 1972, 49, 708.

9. Brenelli, E. C. S.; Quim. Nova 2005, 28, 136.

10. Rocha, W. R.; Cadernos Temáticos de Química Nova na Escola 2001, no. 4,31 .

11. Snyder, L. R.; Kirkland, J. J.; Glajch, J. L.; Practical HPLC Method Development, $2^{\text {nd }}$ ed., Wiley: New York, 1997, cap. 15.

12. de Andrade, J. B.; Pinheiro, H. L. C.; Lopes, W. A.; Martins, S.; Amorim, M. M.; Quim. Nova 1995, 18, 379.

13. Bispo, M. S.; Veloso, M. C. C.; Pinheiro, H. L. C.; de Oliveira, R. F. S.; Reis, J. O. N.; de Andrade, J. B.; J. Chromatogr. Sci. 2002, 40, 45.

14. Pérez- Martínez, I.; Sagrado, S.; Medina-Hernández, M. J.; Anal. Chim. Acta 1995, 304,195.

15. Ferreira, S. L. C.; Bruns, R. E.; da Silva, E. G. P.; dos Santos, W. N. L; Quintella, C. M.; David, J. M.; de Andrade, J. B.; Breitkreitz, M. C.; Jardim, I. C. S. F.; Neto, B. B.; J. Chromatogr., A 2007,1158, 2.

16. Ferreira, S. L. C.; dos Santos, W. N. L.; Quintella, C. M.; Neto, B. B.; Bosque-Sendra, J. M.; Talanta 2004, 63, 1061.

17. Sousa, E. T.; Rodrigues, F. M.; Martins, C. C.; de Oliveira, F. S.; Pereira, P. A. P.; de Andrade, J. B.; Microchem. J. 2006, 82, 142.

18. de Aragão, N. M.; Veloso, M. C. C.; Bispo, M. S.; Ferreira, S. L. C.; de Andrade, J. B.; Talanta 2005, 67, 1007.

19. Statistica for Windows, StatSoft, Inc, 2300 East $14^{\text {th }}$ Street, Tulsa, OK 741014, USA, 1999. 